\title{
ATUAÇÃO DO REVISOR DE TEXTOS: UMA EXPERIÊNCIA NO SESC DE MINAS GERAIS
}

\author{
PROOFREADER'S ACTIVITIES: AN INSTITUTIONAL EXPERIENCE AT SESC \\ MINAS GERAIS
}

M. R. ROMANO ${ }^{1, *}$, A. E. RIBEIRO'

${ }^{1}$ Centro Federal de Educação Tecnológica de Minas Gerais, Programa de Pós-Graduação em Estudos de Linguagens, Brasil

\author{
ARTICLE INFO \\ Palavras-chave: Revisão de texto. Ritos genéticos \\ Article history: \\ editoriais. Coenunciação. Sesc. \\ Received 2018-07-02 \\ Accepted 2018-08-17 \\ Available online 2018-08-31 \\ Keywords: Proofreading. Genetic editorial rits. \\ ${ }^{*}$ Autor correspondente: \\ E-mail: marciaromano2006@gmail.com
}

RESUMO. Neste trabalho, à luz da análise do discurso de Dominique Maingueneau ([1995] 2008a, [1998] 2008b) e de uma proposta de Luciana Salazar Salgado (2013; 2016) que considera a revisão de textos como coenunciação, além de aspectos da ergologia (SCHWARTZ, 1998; 2014), apresentamos a experiência institucional de produção editorial, em especial com peças publicitárias, na instituição Serviço Social do Comércio (Sesc) de Minas Gerais. Composta a partir de 2012, a equipe responsável pelas peças gráficas e digitais institucionais conta com uma revisora contratada, entre outros profissionais. Mostramos como a equipe se constituiu e quais os seus processos de trabalho, especialmente o da revisora. A fim de dar mais foco às questões aqui tratadas, analisamos brevemente uma peça institucional em seu processo de produção e revisão textual. Concluímos que os processos de revisão foram se aperfeiçoando à medida que o trabalho foi sendo vivenciado e experimentado, além de explicitarmos as questões coenunciativas que emergem da interação entre revisora e outros profissionais.

ABSTRACT. In this work, based in Dominique Maingueneau's discourse analysis ([1995] 2008a, [1998] 2008b) and in Brazilian researcher Luciana Salazar Salgado's (2013; 2016) proposal that considers proofreading as co-enunciation, besides some ergologic aspects (SCHWARTZ, 1998; 2014), we present an institutional experience of editorial production, especially of advertising texts, at Serviço Social do Comércio (Sesc) from Minas Gerais. Created in 2012, the team responsible for the graphic and digital institutional texts has a proof-reader under contract, among other professionals. We show how the team was constituted and what are its work processes, especially the proof-reader's. In order to give more focus to the issues discussed here, we briefly analysed an institutional piece in its textual production and correction processes. We conclude that the proofreading processes were improved as the work was being experienced, and we also try to make clear the co-enunciative issues that emerge from the interaction between the proof-reader and the other professionals. 


\section{Introdução 1}

"O texto está pronto, já pode passar pra revisão e depois envia pra gráfica". Quantas vezes, em um ambiente de trabalho dedicado à produção editorial - uma editora ou uma agência de comunicação, entre outros -, essa frase discutível foi enunciada, como se a revisão fosse sempre a última etapa do processo de produção de um texto que se destina à publicação? A visão de que o trabalho de revisão se restringe a "corrigir erros de ortografia", como algo que não afeta o texto, em sentido amplo, é, além de limitante, errônea.

$\mathrm{Na}$ prática, o texto, quando chega às mãos do profissional de revisão, está apenas iniciando um novo processo, que é o da leitura, ou melhor, de novas leituras, pois o revisor é um leitor "autorizado", é aquele que se coloca como um outro do autor, que enseja possíveis futuras leituras e faz com que o autor tenha um outro olhar sobre sua produção, colocandose como leitor de seu próprio texto. Esse movimento sobre o texto, mais uma vez, desnuda os fios ideológicos dessa complexa trama e mostra que a enunciação é sempre coenunciação, pois há sempre a presença do outro. E é assim que o texto volta da revisão repleto de marcações, alterações, questionamentos e dúvidas.

Em geral, o autor não tem outra opção senão responder a essas dúvidas, ou seja, estabelecer o pacto de dialogar com o revisor para pensar novas formas de dizer o que deu margem a dúvida, polêmica ou mesmo o que não estava em conformidade com o público leitor ou com o gênero da publicação. Esse pacto, quando firmado de parte a parte, só tem a acrescentar ao trabalho. Afinal, quanto mais bem elaborado um texto, melhor - é o que presumimos. O diálogo pode ocorrer de fato, por meio de trocas de mensagens e conversas, ou em silêncio, quando o autor revê o próprio texto, depois da atuação do revisor.

Nota-se que a revisão é um trabalho de sujeitos que envolve inúmeras decisões. De que forma aplicar as regras gramaticais? Qual é o tom exato para esse público? São decisões que envolvem os saberes acumulados de quem se detém sobre um texto, além de valores e normas concernentes à instituição que o publica. Neste trabalho, assumindo que um revisor seja sempre, ainda que apagado ou invisibilizado, um coenunciador, nos deteremos no processo editorial e de revisão textual que ocorre dentro de uma instituição brasileira relevante, o Serviço Social do Comércio (Sesc) - unidade regional Minas Gerais. Uma das autoras deste trabalho é revisora de textos no Sesc desde julho de 2012, o que suscitou o interesse pelo tema. Por meio de um relato de experiência, pretende-se analisar de que forma a participação do revisor na elaboração dos textos foi se transformando ao longo do tempo, indicando a vitalidade das relações laborais cotidianas no trabalho com a língua.

\footnotetext{
${ }^{1}$ Este trabalho é parte da pesquisa de mestrado empreendida pelas autoras, na qualidade de orientanda e
} orientadora, no PPG em Estudos de Linguagens do CEFET-MG, na linha IV - Edição, Linguagem e Tecnologia. 
Nossa hipótese é que este trabalho contribua para a compreensão dessas relações como um processo de construção de sujeitos que produzem em conjunto e assim se constituem na e pela língua. Busca-se, por conseguinte, apresentar a natureza da atuação do revisor de textos na organização Sesc, analisando a evolução dessa atuação ao longo do tempo; trazer como corpus de análise um texto publicitário: comparar o texto original com a versão final, apontando os movimentos de sentido empreendidos durante a revisão de textos e os diálogos entre autor e revisor de textos, a fim de compreender como os caminhos do texto vão sendo delineados; analisar, sob o prisma dessa evolução da atuação do ofício de revisão no Sesc, um trabalho desenvolvido sob uma nova perspectiva.

\section{Revisão, peças publicitárias e afins no Sesc de Minas Gerais: uma fundamentação para o estudo}

Quando se trata da revisão de textos publicitários, há todo um universo de sentido a ser compreendido, além de um sistema de coerções a ser obedecido. Esse tipo de texto faz parte da cultura das sociedades contemporâneas, na medida em que todas as pessoas que o consomem se relacionam com organizações privadas e, assim, são alvo da comunicação destas ou leitores dessa produção textual. Todos leem, em alguma medida, tal tipo de texto. Assim, os discursos produzidos pelas organizações estão inscritos na circulação da energia social, já que são influenciados pela sociedade e, ao mesmo tempo, a influenciam, num movimento de troca constante, o que contribui para que se configure a forma como nos vemos e como nos relacionamos com o mundo. Portanto, analisar a produção editorial de textos publicitários ajuda a compreender as formas de organização social contemporâneas no que tange à circulação de discursos. E, mais especificamente, entender os movimentos realizados pelo revisor de textos nesses ambientes de trabalho - as organizações - contribui para a percepção das práticas linguageiras e dos processos de construção de sentido nesse universo.

Para fundamentar teoricamente este estudo, são importantes a análise do discurso de matriz francesa, sobretudo em Dominique Maingueneau ([1995] 2008a, [1998] 2008b), a noção de ritos genéticos editoriais desenvolvida por Luciana Salazar Salgado (2013; 2016), a ergologia (SCHWARTZ, 1998; 2014) e as discussões realizadas por José Muniz Júnior (2010) sobre a relação entre os estudos do trabalho e os estudos do discurso e da revisão de textos.

O primeiro conceito importante aqui é o de discurso. Para Salgado (2016, p. 46), discursos "são sistemas de restrições semânticas (de condicionamento dos sentidos dos dizeres) indissociáveis das práticas sócio-históricas (condicionantes dos lugares e dos modos de dizer)". Maingueneau, em quem Salgado também se fundamenta, afirma que o discurso 
tanto o conjunto de textos produzidos por comunistas, quanto o sistema que permite produzir esses textos e outros ainda, igualmente qualificados como textos comunistas ([1998] 2008b, p. 51).

Importa-nos aqui relacionar o discurso com as práticas humanas de significação, de produção da existência humana. Conforme Muniz Júnior,

o discurso deve ser entendido como "forma de prática social e não como atividade puramente individual ou reflexo de variáveis situacionais" (FAIRCLOUGH, 2001, p. 90). Sobre essas bases a linguagem será pensada como produção da humanidade - e, por isso, marcada por suas contradições. A perspectiva discursiva é, pois, aquela que "trata da determinação histórica dos processos de significação" (ORLANDI, 1987, p. 12). Suas contribuições têm sido incorporadas a diversas ciências humanas: reconhece-se o papel do discurso em constituir relações sociais e de poder, e vice-versa (2010, p. 253254).

Tais "relações sociais e de poder" são caras ao texto publicitário, pois é por meio de seu discurso que uma organização se afirma perante as outras e conquista seu público. Essa noção é importante para o revisor de textos, que aplica em sua prática cotidiana os conceitos de ethos e fiador do discurso, já que, ao revisar textos publicitários, é preciso pensar que há uma voz que fala, um "sujeito" que se coloca, que transmite a mensagem da empresa/instituição em questão, engendrando um tom ao discurso.

O próprio "tom" se apoia sobre uma dupla figura do enunciador, a de um caráter e a de uma corporalidade, estreitamente associadas. Com efeito, o rosto que suporta o tom deve ser caracterizado "psicologicamente", ver-se dotado por disposições mentais que sejam o correlato dos afetos que o modo de enunciação engendra (MAINGUENEAU, [1995] 2008a, p. 92).

Trata-se do conceito de ethos: por meio da enunciação, a personalidade do enunciador é revelada. As empresas, em campanhas publicitárias veiculadas nos meios de comunicação, escolhem como vão se mostrar. Se é uma empresa que valoriza a mulher, a diversidade, a quebra de preconceitos, enfim, o que estiver em pauta nas discussões entre as pessoas em uma dada comunidade e sendo visto como valor. "Roland Barthes salientou a característica essencial desse ethos: 'São os traços de caráter que o orador deve mostrar ao auditório (pouco importa sua sinceridade) para causar boa impressão: são os ares que assume ao se apresentar [...]"” (MAINGUENEAU, [1998] 2008b, p. 97-98).

O conceito de ethos faz emergir "uma instância subjetiva que desempenha o papel de fiador do que é dito" (p. 98). Para que a persuasão se efetive, fiador e público precisam partilhar do mesmo ethos, para que o público se identifique com o que é dito e the confira legitimidade.

Em última instância, a questão do ethos está ligada à da construção da identidade. Cada tomada da palavra implica, ao mesmo tempo, levar em conta representações que os parceiros fazem um do outro e a estratégia de fala de um locutor que orienta o discurso de forma a sugerir através dele certa identidade (MAINGUENEAU, [1998] 2008b, p. 59-60). 
Essa construção da identidade é feita no momento da produção do discurso, mas também no da revisão. Grosso modo, o que se espera de um revisor de textos é que ele "corrija" um texto, do ponto de vista das normas gramaticais vigentes. Porém, o que norteia a escolha do revisor quanto aos dicionários e às gramáticas adotados? Ou, ainda: o mais adequado seria seguir um manual de normas de alguma casa editora ou jornal, ou vamos criar o nosso próprio? Quando aplicar a norma culta e quando não aplicar?

De acordo com Muniz Júnior, "a norma é um dispositivo de prescrição organizado discursivamente" (2010, p. 256), já que está presente de forma explícita (gramáticas e manuais de redação) ou tácita (regras do gênero, rituais e costumes específicos de cada órgão publicador). Segundo o autor, as normas

só podem ser pensadas a partir das condições históricas em que foram engendradas e nas quais continuam produzindo sentido. Elas fornecem diretrizes para a atividade e revelam o caráter coletivo do trabalho por meio das vozes normativas de outros eus que deixaram seu registro de ação e coerção no decorrer do tempo (p. 256).

\section{Olhares sobre a atividade de revisão de textos: breve revisão da literatura}

Revisor de textos, revisor ortográfico, copidesque, preparador de textos, editor... São denominações que designam as diferentes etapas do trabalho de intervenção textual e que fazem parte do processo de produção editorial. A obra Em busca do texto perfeito (RIBEIRO, 2016) discute o significado específico de cada termo, além de trazer discussões sobre as normas e práticas de revisão textual. Os limites e as contiguidades entre as atuações de profissionais chamados amplamente de "revisores" sempre foram controversos e sempre suscitaram dúvidas. Em razão disso, alguns trabalhos foram feitos a fim de contribuir para a discussão sobre a formação, a atuação e o perfil dos revisores.

O perfil do profissional de revisão de textos que atua em Minas Gerais foi a preocupação principal da dissertação Revisor de textos: concepções e formação do profissional em Minas Gerais (NASCIMENTO, 2014). A partir do aporte teórico da Linguística Textual, foram analisados aspectos relativos à formação do profissional e as concepções de texto e de revisão que subjazem à atividade dos profissionais. Especificamente em relação ao revisor de textos atuante em agências de publicidade, a dissertação "Quem mexeu no meu texto?": Língua, poder e autoria nos dizeres sobre o revisor de textos da publicidade (NOBLE, 2016) oferece uma análise dos dizeres em relação ao revisor de textos nesses ambientes, a partir de entrevistas com profissionais, utilizando-se da análise do discurso pêcheuxtiana.

$A$ atividade de intervenção textual como ato dialógico é objeto de análise no artigo "A intervenção textual como atividade discursiva: considerações sobre o laço social da linguagem no trabalho de edição, preparação e revisão de textos" (MUNIZ JÚNIOR, 2009). Contribuem para a pesquisa os estudos sobre os discursos, com os debates sobre regimes de 
genericidade e de normatividade, sob a perspectiva do trabalho. Nessa mesma linha, o artigo "A atividade de trabalho do revisor de textos acadêmicos em análise dialógica e ergológica" (BARBOSA, 2016) coloca em diálogo a ergologia e os estudos do discurso, advindos dos pressupostos bakhtinianos da linguagem, a fim de discutir a revisão de textos acadêmicos.

Neste ponto, estabelecemos uma relação dos estudos sobre o discurso com a perspectiva ergológica, a qual se preocupa com o cotidiano do trabalhador a fim de renovar as maneiras de ver o trabalho. De acordo com essa perspectiva, o trabalho tem a função de preencher a lacuna existente entre o prescrito e o real. Assim é que, nas situações cotidianas, o trabalhador confronta as normas precedentes com a necessidade de dar respostas em cada atividade que realiza.

[...] toda sequência de atividades industriosas envolve arbitragens, debates, imersos num mundo social em que a comunidade de destino é sempre eminentemente problemática, em permanente reconstrução. Advêm dessas arbitragens decisões sempre parcialmente não antecipáveis, "renormalizações"; mesmo num nível infinitamente pequeno, os resultados dessas arbitragens - as "renormalizações" - recriam sem cessar uma história: "ocorre continuamente algo novo" que, obrigando-nos a escolher, forçam-nos a nos escolher, na qualidade de seres às voltas com um mundo de valores. Daí vem a ideia de que esse uso de si é uma imposição contínua dessas microescolhas permanentes e disso surge a expressão do trabalho como dramática do uso de si (SCHWARTZ, 2014, p. 261).

Em nosso trabalho, temos de fazer escolhas o tempo todo. Temos diante de nós as normas que nos são impostas, mas também as normas tradicionais de cada tipo de trabalho e a "memória da atividade", ou seja, um conjunto de expectativas decorrente da construção histórica coletiva de cada atividade. Entre esse conjunto de normas e a prática, existe um hiato, que é preenchido pela atividade laboral do sujeito. Para realizar essa atividade que preenche lacunas, o trabalhador tem diante de si a "dramática do uso de si", ou seja, tem sempre de colocar em jogo a sua subjetividade a fim de fazer escolhas para criar e recriar de forma incessante, pois cada situação de trabalho é nova. No caso do trabalho de revisão de textos, tem-se, conforme Muniz Júnior, "a intersecção entre textos e normas" (2010, p. 256).

Quando faz uma emenda, o profissional está (i) retomando dizeres das prescrições (dicionários, gramáticas, manuais da editora, da coleção ou do coletivo, regras do gênero etc.); (ii) dirigindo-se a interlocutores que terão acesso direto a suas emendas: chefias, autores, colegas, diagramadores etc.; (iii) dirigindo-se, ao habitar a própria autoria, aos leitores/consumidores finais do livro em questão (p. 256).

A dramática do revisor se realiza discursivamente, no plano da textualização. Ele coloca em diálogo três instâncias: as normas de escrita, seus interlocutores e seus leitores. Pensar nesses "leitores/consumidores finais" é de fundamental importância para o trabalho de revisão de textos. No caso dos textos publicitários, ter em mente a informação a respeito do público-alvo (e do suporte) de cada texto direciona o olhar. "Toda enunciação contempla manobras interlocutivas que procuram controlar a interpretação do que se diz com base em 
expectativas construídas entre os interlocutores - sobre si mesmos, sobre o outro, sobre o outro desse outro de si" (SALGADO, 2016, p. 131-132). Mais do que isso, a enunciação não tem sentido se não for significante para todos os enunciadores. Maingueneau propõe as seguintes instâncias:

[...] leitor invocado, um interlocutor que é explicitado nos vocativos do texto; outra, a que chama leitor instituído, instância que a própria enunciação implica; e as noções de público genérico, caracterizado socialmente conforme o gênero da publicação, e de público atestado, aquele que efetivamente entra em contato com a publicação. Com base nessas distinções, fala em leitor cooperativo, aproximando-o do Leitor Modelo de Umberto Eco, para pôr em relevo a organização textual, de modo que se entenda que a leitura cooperativa não é uma atividade que responde "às intenções do escritor, mas às indicações oferecidas pelo texto por sua conformação e suas prescrições virtuais de decifração" (MAINGUENEAU, 1996, p. 38 apud SALGADO, 2016, p. 132).

\title{
3.1. A revisão de textos como coenunciação
}

A fim de tratar da interlocução existente na produção textual, é posta em cena a noção de coenunciador: "correlativo de enunciador, para acentuar que a enunciação é, de fato, uma coenunciação, na qual dois participantes desempenham um papel ativo (CHARAUDEAU; MAINGUENEAU, 2004, p. 155 apud SALGADO, 2016, p. 131). No processo de tratamento editorial de textos, Salgado denomina o revisor de textos de coenunciador editorial.

\begin{abstract}
Nessa dinâmica, diversos lugares discursivos se põem como pontos nodais de uma rede. O lugar de autor é um deles, é um móbil de certas trocas. O lugar de coenunciador editorial é outro, conexo ao de autor. Dele, um leitor profissional oferece ao autor a explicitação da interlocução que todo texto supõe (e, no caso das publicações, pretende), e o autor pode tomar distância de seu texto, voltando a ele para produzir uma versão pública consistente. [...] O ofício de escrever supõe sempre que haverá trabalho de um outro, isto é, que um outro correrá umas linhas, tardará noutras e é provável que tropece lá e cá, pois o encontro entre sujeitos é sempre no caminho, caminhantes que são os sujeitos ao se porem nas cenas de enunciação (e as leituras, como as escrituras, são modos de pôr-se nessas cenas) [...]. (SALGADO, 2013, p. 275-276).
\end{abstract}

A autora se debruça sobre o processo de produção editorial e, desdobrando o conceito de ritos genéticos, de Maingueneau ([1995] 2008a), estabelece a noção de ritos genéticos editoriais para o tratamento editorial dos textos que se destinam à publicação e, mais especificamente, a revisão de textos.

Para entender melhor esse ofício, que, no limite, opera na "vitalidade dos textos", proponho que seja entendido como parte do que chamarei ritos genéticos editoriais: no processo editorial, os originais do autor passam por diversas etapas de constituição do texto que vai a público; em certa medida, esse texto ainda está sendo escrito, e essa etapa autoral inclui a leitura de um outro autorizado a fazer intervenções (difíceis de discriminar previamente) em diversos âmbitos do texto (difícil prever até que ponto) (SALGADO, 2016, p. 162, grifos da autora). 
Conforme os ritos genéticos editorias, o coenunciador editorial é aquele que oferece ao autor a sua leitura, aponta caminhos de interpretação e direções para possíveis releituras e reescritas, sempre considerando os âmbitos extralinguísticos que constituem a produção de sentido, numa atividade de textualização que abre uma vez mais o texto antes da publicação, propondo-se a uma interlocução marcada. Marcada fisicamente, em cada sugestão de alteração que o coenunciador propõe ao autor e recebe dele uma réplica, que dá origem a uma tréplica, até que o texto se configure como final.

Assim, entendemos que a perspectiva dos ritos genéticos editoriais seja uma das formas pelas quais "as dramáticas do uso de si" (SCHWARTZ, 2014, p. 261) se realizam, na prática, no cotidiano do trabalho de revisão de textos. As renormalizações, as arbitragens, os debates, todos estreitamente relacionados a um universo de valores, estão presentes na interlocução que se firma entre enunciador e coenunciador editorial. São escolhas, negociações, entre dois sujeitos sociais, que imprimem em cada trabalho sua energia, sua concentração, seus conhecimentos e valores, enfim, algo de si.

Dramatique: situação em que o indivíduo tem de fazer escolhas, ou seja, arbitrar entre valores diferentes, e, às vezes, contraditórios. Uma dramatique é portanto, o lugar de uma verdadeira micro-história, essencialmente inaparente, na qual cada um se vê na obrigação de se escolher, ao escolher orientar sua atividade de tal ou tal modo. Afirmar que a atividade de trabalho não é senão uma dramatique do uso de si significa ir de encontro à ideia de que o trabalho é, para a maioria dos trabalhadores, uma atividade simples de "execução", que não envolve realmente sua pessoa. (N. do autor) (SCHWARTZ, 1998, p. 58).

Partimos do princípio que é justamente esse "envolver sua pessoa" que faz diferença no caso do trabalho com o texto, nosso objeto de estudo, já que não se trata de uma simples atividade de "execução". A interlocução estabelecida entre determinado revisor com determinado autor em cada casa editora é única e é o que vai determinar o texto final. Cada experiência de trabalho - no nosso caso, cada texto revisado - é única. Cada texto publicado teve, assim, seu rito genético editorial.

\section{Procedimentos metodológicos e relato de uma experiência}

Para a realização deste trabalho, foi escolhida a instituição Serviço Social do Comércio (Sesc) de Minas Gerais. Uma das autoras, como já dito, é revisora de textos na instituição desde julho de 2012, o que lhe permitiu observar na prática os preceitos dos ritos genéticos editoriais no cotidiano de trabalho e acompanhar algumas etapas do processo de produção dos textos, bem como ter acesso ao contexto de produção de cada discurso.

A primeira parte da análise apresentada neste artigo é um relato da experiência com a revisão de textos realizada na Assessoria de Comunicação do Sesc entre os anos de 2012 
e 2017. Será apresentada a evolução dessa atuação ao longo do tempo, da perspectiva da ergologia, em diálogo com a noção de ritos genéticos editoriais.

Em seguida, será analisado um texto publicitário sob o viés da análise do discurso de matriz francesa, comparando o texto original com a versão final, apontando os movimentos de sentido empreendidos durante a revisão de textos e os diálogos entre autor e revisor de textos para compreender como os caminhos do texto vão sendo delineados.

Por fim, será analisado, sob o prisma dessa evolução da atuação do ofício de revisão no Sesc anteriormente descrita, um trabalho desenvolvido sob uma nova perspectiva.

\subsection{Formação de equipe no Sesc de Minas Gerais}

Normalmente, as organizações terceirizam o trabalho de produção editorial de suas publicações: os materiais de divulgação (campanhas publicitárias nos vários meios (TV, rádio, internet e mídia impressa), páginas na internet, participações nas redes sociais, e-mail marketing, cartazes, folhetos, livretos) são produzidos externamente, por agências de comunicação, e apenas supervisionados por profissionais da equipe de Comunicação da organização, como jornalistas e relações públicas. Mas o Sesc é uma das instituições em que o trabalho é todo elaborado internamente. Assim, em julho de 2012, uma revisora de textos foi selecionada para integrar a equipe da Assessoria de Comunicação do Sesc.

Incialmente, foi preciso conhecer a organização, seu funcionamento e o conjunto dos materiais de divulgação com que o Sesc lidava na época. Não havia manual de normas e estilo, nem um padrão para as publicações, pois não havia revisor antes. Aos poucos, os padrões foram sendo definidos, de acordo com o que funcionava e com as necessidades das publicações. A identidade da organização foi sendo construída e seu ethos foi sendo definido, em consonância com o contexto social do qual fazemos parte.

Em ambientes onde trabalham profissionais de diferentes formações, mas dentro da mesma área de atuação, é natural que os conhecimentos adquiram caráter de fronteira, pois são sempre postos em diálogo, em intercâmbio entre os sujeitos, porque estão a serviço do trabalho a ser entregue. Ainda que não se trate de autores escrevendo para si, como no caso dos trabalhos autorais, não se pode desconsiderar as características pessoais de cada sujeito e, sobretudo, como isso impacta sua forma particular de compreender a instituição, ou seja, os "usos de si" (SCHWARTZ, 2014). E assim, de dramática em dramática, os ritos genéticos editoriais foram se desenrolando à medida que os diversos profissionais da Comunicação (revisor, jornalista, relações públicas, designer, coordenações) foram estabelecendo um fluxo de trabalho e, em consequência, um relacionamento profissional e pessoal.

Como no início não havia a figura do redator publicitário - o que é vital para a elaboração de textos publicitários, por ironia -, os textos eram construídos em parceria entre todos os profissionais mencionados. Essa ausência foi corrigida em 2016, mas até então 
contribuiu para que se estabelecesse a dinâmica do trabalho coletivo, distante da exacerbação de ego que se verifica em agências de publicidade, em que o redator ocupa um lugar intocável. Assim, quando a função da redatora foi instituída, a dinâmica do trabalho colaborativo se manteve, mas os demais profissionais foram "liberados" da árdua tarefa de produção de textos, e apenas a revisora passou a colaborar com a redatora. Assim, enunciadora (redatora) e coenunciadora (revisora) transformaram-se em dupla de criação.

Sobre as normas, foi elaborado o Manual de escrita corporativa, publicação de circulação interna, a partir dos melhores usos de padrões verificados no uso de outras organizações. Cada padrão (grafia de horas, preços, localidades, usos de pontuação) era testado em cada peça publicitária para, enfim, compor a norma, sempre de forma a fazer sentido, sobretudo para os designers, afinal, a leiturabilidade ${ }^{2}$ e o aproveitamento do espaço são aspectos cruciais para peças de divulgação que se destinam a persuadir o público, tendo como foco principalmente as instâncias de leitor instituído e público atestado.

Também constam neste Manual as nomenclaturas da organização, definidas em âmbito nacional, as formas de se apresentar (como instituição e não como empresa), a compreensão de sua estrutura física (unidades operacionais, unidades de hospedagem, centro cultural, etc.), o entendimento de sua estrutura de funcionamento (divisão em áreas de atuação), as normas para a comunicação com os públicos (por exemplo, a forma de se dirigir aos idosos, às pessoas com deficiência), entre outros aspectos. Normalizações e renormalizações foram sendo operadas até se chegar a um ponto ideal, que funcionasse para as necessidades diárias. Esse Manual transformou-se em um curso de capacitação, denominado Sesc em palavras, que é ministrado para todos os funcionários, inclusive a diretoria, juntamente com o Media training, que trata do relacionamento com a imprensa. A perspectiva é que a capacitação assuma o formato de videoaulas para os funcionários do interior do estado.

No início, a estação de trabalho da revisora se localizava no final da sala, num cantinho silencioso, mas isolado do resto da equipe, já que seu trabalho era visto como solitário e que só acontecia no final do processo de produção, ou seja, "antes do envio pra gráfica". Mas, era constante a interação com os colegas, pois, no momento da entrega das demandas, sempre era necessário dialogar com os profissionais das demais etapas do processo, para explicar as alterações, sugerir outras mais substanciais, tirar dúvidas.

Num segundo momento, a revisora passou a ser consultada antes da elaboração das publicações, para que o trabalho fosse otimizado. Os debates eram cada vez mais frutíferos, e as produções, cada vez mais coletivas. O trabalho desenvolvido pela Assessoria passou a

\footnotetext{
2 Conforme Gruszynski (2007, p. 152), esse termo "refere-se ao agrupamento de tipos em palavras, frases, parágrafos, de modo que a informação verbal seja o mais facilmente apreendida. Este fator não é determinado apenas pela composição tipográfica, mas também em função do texto em si, seu vocabulário, estrutura frasal, etc."
} 
ser citado nos encontros nacionais da organização, e os profissionais do Sesc muitas vezes eram designados para contribuir nas organizações irmãs, o Senac e a Fecomércio.

Num terceiro momento, a revisora passou a assumir uma função mais estratégica, participando de reuniões para definição dos direcionamentos no que tange à construção do discurso. Um novo desafio, já que as tarefas de revisão propriamente não foram destinadas a outra pessoa.

Verifica-se que o cuidado com a língua para os dirigentes do Sesc é um valor, pois há um entendimento de sua importância para a construção da imagem da organização. Em um mercado de trabalho em que as Assessorias de Comunicação são enxutas, vistas como desnecessárias e as primeiras a sofrerem cortes em momentos de crise, é um sinal desse valor que a equipe de Comunicação do Sesc, que é a maior da organização, tenha se mantido intacta em época de contenção de despesas.

Quanto à experiência da profissional de revisão de textos no Sesc, pode-se dizer que é a língua, inerente a todo ser humano, o fio condutor dessa "dramática do uso de si" a que são submetidos em seu cotidiano os profissionais de uma empresa, sobretudo no setor de Comunicação. É importante ressaltar que a revisora não se transformou em editora, o que seria outra função, mas a sua atuação como a profissional referência em texto se configurou como a profissional referência em discurso, como correlato de referência em usos da língua, por assim dizer, de acordo com o desenvolvimento dos ritos genéticos editoriais e com o entendimento que se criou ao longo do tempo, ou seja, com os pactos que se estabeleceram entre os sujeitos do trabalho.

\section{Uma análise textual}

A peça analisada como exemplo do trabalho no Sesc (Figura 1) é um anúncio para um jornal de grande circulação. Trata-se de uma manifestação da instituição a respeito do aniversário de 120 anos Belo Horizonte, comemorado em dezembro de 2017. A ideia era mostrar como o Sesc faz parte da história da cidade, mostrando uma foto de sua unidade mais antiga. A peça é também um desdobramento da campanha institucional veiculada à época nos meios de comunicação com o mote "Sesc: a gente quer mais pra vida". Por isso o mote do anúncio é "A gente quer mais pra BH". 


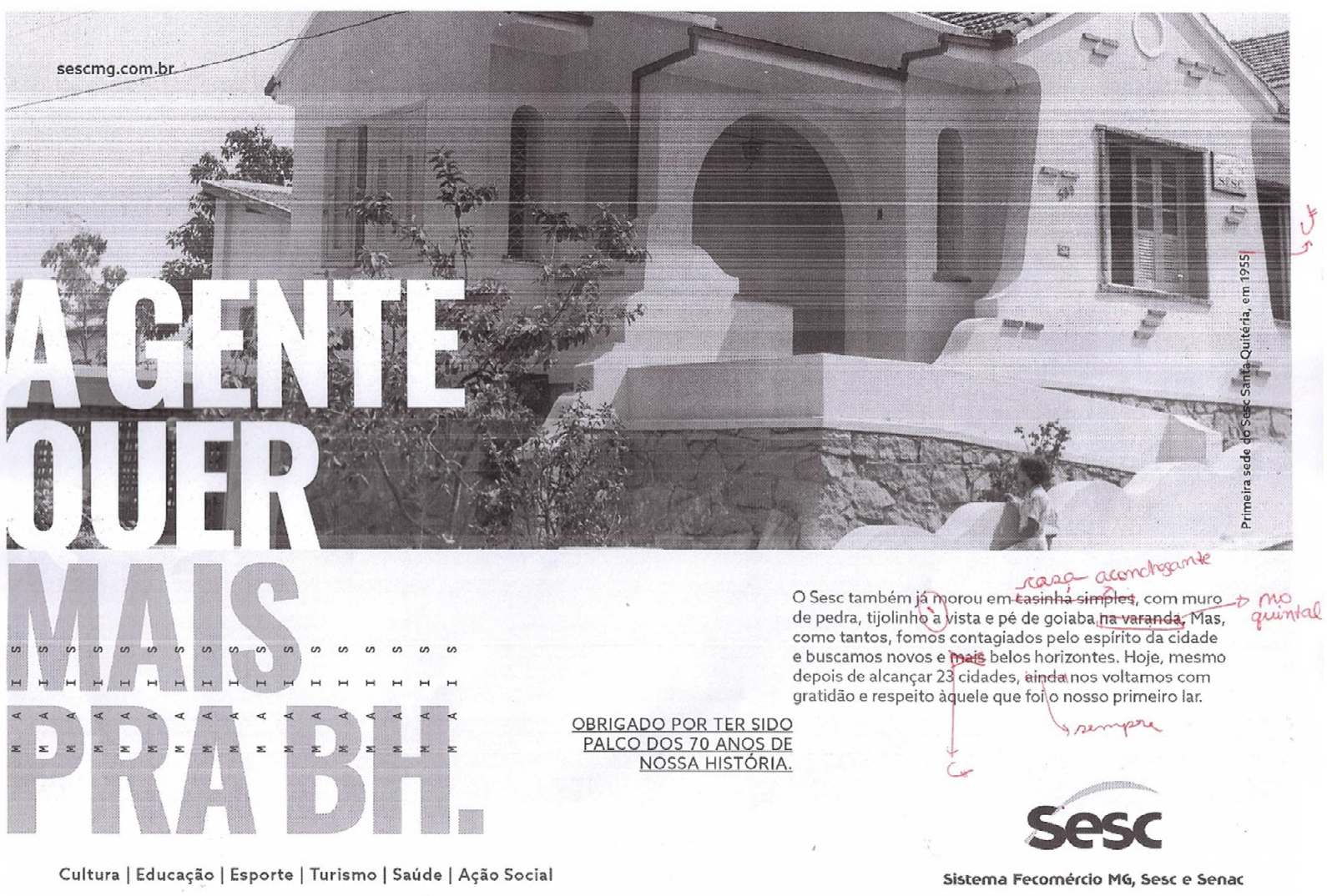

Figura 1 - Anúncio do Sesc em processo de revisão

Fonte: Acervo do Sesc (2018)

Sobre o texto, as alterações mostram os movimentos de sentido realizados no momento da revisão. O primeiro deles foi a sugestão da exclusão da palavra mais (linha 4), para fugir do entendimento de que as novas sedes, conceito expresso em "belos horizontes" seriam mais belas que a casinha da década de 1950. Isso daria a ideia de que o Sesc não valoriza a tradição, o antigo. Ao mesmo tempo, manteve-se "novos e belos horizontes" para remeter à evolução da organização e ao nome da cidade. O trabalho de revisão de textos busca sempre manter o conceito criativo do autor, mas mostrando os caminhos de interpretação que sua escrita direciona e propondo outras soluções. Ainda nessa primeira leitura e na mesma linha de raciocínio, sugeriu-se a substituição da palavra ainda por sempre, pois o advérbio usado anteriormente reforçava essa ideia de desvalorização da tradição. $O$ advérbio sempre intencionou mostrar uma postura de reverência diante desse "primeiro lar", mesmo "depois de alcançar 23 cidades".

Essa leitura fez com que a redatora se colocasse na posição de leitora do jornal, o público genérico, e reavaliasse os dêiticos espaciais casinha simples e varanda. Este último foi substituído por quintal, para que o leitor não perdesse energia se perguntando algo do tipo "Mas o pé de goiaba não está na varanda..." e imaginando que o pessoal do Sesc não toma cuidado com as palavras. Já casinha simples causava incômodo para a redatora, pois, ainda que $o$ intuito fosse apelar para o afetivo, poderia dar margem a interpretações reducionistas, 
de casa pequena e pobre. Nessa discussão, participou outra profissional, uma relações públicas, que a fez entender o motivo do incômodo, explicando: "minha avó tem uma casa desse jeitinho num bairro de $\mathrm{BH}$, e, se ela lesse esse anúncio, sentiria raiva do Sesc por chamar a casa dela de 'casinha simples', pois, em seu entendimento, sua casa é ótima". Assim, a expressão casa aconchegante deu uma ideia mais exata do que se queria transmitir, valorizando o imóvel da fotografia e, por consequência, a instituição que ali se posicionava. Enfim, são manobras textuais, realizadas conforme os ritos genéticos editoriais, que visam a contribuir para a melhor construção da imagem da organização, mediante o entendimento das noções de ethos e fiador.

\subsection{Uma nova perspectiva de trabalho}

Conforme mencionado, a revisora de textos, que passou a participar das reuniões para tomada de decisões quanto ao discurso, foi chamada a participar de uma reunião a respeito da aplicação das novas normas para habilitação advindas do órgão nacional do Sesc. Tratase das normas para o recebimento de novos associados. Há uma série de diretrizes quanto ao uso dos termos desse universo, como a distinção entre matrícula e habilitação para esse processo, a forma como devemos nos referir ao público-alvo, entre outros. São prescrições que devemos seguir, mas que, na prática, demandam debates para se chegar a um ponto interessante do ponto de vista da comunicação.

Era preciso aplicar as novas nomenclaturas às peças de divulgação destinadas aos clientes novos e antigos, mas surgiu a dúvida sobre a necessidade de comunicar ao público essas mudanças: apenas trocamos os termos ou precisamos elaborar uma espécie de dicionário do Sesc? A participação da revisora contribuiu para que todos se colocassem no lugar do público e compreendessem a importância de explicar, de forma clara, as mudanças realizadas, a fim de deixar o público à vontade com o universo da instituição, mas também de contribuir para a construção permanente da identidade do Sesc. Além disso, cada termo alterado pelo novo normativo foi discutido do ponto de vista da clareza, de forma alinhada ao ethos do Sesc, e dos usos que são feitos nas peças gráficas. Alguns termos foram adaptados para melhor compreensão do público, e as dúvidas quanto à aplicação das normas foram levantadas de início, já que transformar as diretrizes de documentos normativos oficiais em comunicação é um trabalho que demanda leitura, interpretação e diálogo. É um trabalho de renormalização constante, que exige negociação entre os pares e com a diretoria.

Dessa forma, toda a campanha de divulgação foi direcionada a partir dessas discussões. Os retornos foram positivos por parte do público interno, que se mostrou mais confiante para lidar com as novas nomenclaturas para receber os clientes. Os dilemas em que são colocados os profissionais de Comunicação em situações como essa (nos momentos de 
decisão) puderam, a partir da nova visão do trabalho de revisão de texto, contar com um parceiro importante, o profissional referência em usos da língua.

\section{Considerações finais}

O que o relato de uma experiência pode dizer sobre um campo de trabalho? Sabemos que não se pode generalizar, com base em uma experiência tão local e específica, mas é importante compreender o processo de transformação pelo qual passou o setor de produção editorial da instituição focalizada, neste caso, o Sesc MG. Talvez esta experiência seja típica de um tempo em que os setores que lidam com a produção de textos ainda não se consolidaram ou configuraram suas operações, a despeito de esta ser uma área antiga entre as atividades profissionais no mundo.

Com base na análise do discurso e na proposta de Salgado (2016), resultado de sua tese de doutorado, afinadamente com aspectos da ergologia, intentamos mostrar o processo de formação de uma equipe dedicada à produção editorial e publicitária de relevante instituição mineira, sendo relativamente raro que tal equipe incorpore o profissional de revisão de textos, da forma como tem sido eficientemente feito pelo Sesc. Ao operar com as noções de ritos genéticos - editoriais -, ethos, discurso, entre outras, podemos descrever um cenário importante para a revisão de textos e os estudos do campo editorial, além de registrar o movimento do Sesc e, ampliadamente, do contexto de trabalho do revisor em Minas Gerais. A breve análise da produção de uma peça gráfica - de ampla circulação social, como quase tudo que o Sesc produz - é um ponto exemplar de algo maior, isto é, as mudanças de percepção das relações profissionais no campo da edição, dentro de uma instituição, mas também das relações entre esta atuação profissional e a circulação social dos textos e dos discursos.

\section{Agradecimento}

Agradecemos a ajuda de Sérgio Karam com Resumo e Abstract.

\section{Referências}

BARBOSA, Vanessa Fonseca. A atividade de trabalho do revisor de textos acadêmicos em análise dialógica e ergológica. In: COLÓQUIO DE LINGUÍSTICA, LITERATURA E ESCRITA CRIATIVA [DES]LIMIARES DA LINGUAGEM, 9, 2016, Porto Alegre. IX Colóquio de Linguística, Literatura e Escrita Criativa [Des]Limiares da Linguagem. Porto Alegre: PUCRS, 2016.

GRUSZYNSKI, Ana Cláudia. A imagem da palavra: retórica tipográfica na pós-modernidade. Teresópolis: Novas Ideias, 2007. 
MAINGUENEAU, Dominique. (1995) Gênese dos discursos. Trad. de Sírio Possenti. São Paulo: Parábola Editorial, 2008a.

MAINGUENEAU, Dominique. (1998) Análise de textos de comunicação. Trad. de Cecília Pérez de Souza-e-Silva. 5. ed. São Paulo: Cortez, 2008b.

MUNIZ JÚNIOR, José de Souza. A intervenção textual como atividade discursiva: considerações sobre o laço social da linguagem no trabalho de edição, preparação e revisão de textos. In: CONGRESSO BRASILEIRO DE CIÊNCIAS DA COMUNICAÇÃO, 32, 2009, Curitiba. Intercom: XXXII Congresso Brasileiro de Ciências da Comunicação. Curitiba: UP, 2009.

MUNIZ JÚNIOR, José de Souza. Uma perspectiva ergodialógica sobre a atividade de editores, preparadores e revisores na produção de livros. In: SEMINÁRIO INTERNACIONAL DE TEXTO, ENUNCIAÇÃO E DISCURSO, 2010, Porto Alegre. Seminário Internacional de Texto, Enunciação e Discurso. Porto Alegre: PUCRS, 2010.

NASCIMENTO, Lourdes da Silva do. Revisor de textos: concepções e formação do profissional em Minas Gerais. Belo Horizonte, 2014. 136 f. Dissertação (Mestrado em Estudos de Linguagens) - Programa de Pós-Graduação em Estudos de Linguagens, Centro Federal de Educação Tecnológica de Minas Gerais, 2014.

NOBLE, Debbie Mello. “Quem mexeu no meu texto?”: língua, poder e autoria nos dizeres sobre o revisor de textos da publicidade. Porto Alegre, 2016. 123 f. Dissertação (Mestrado em Estudos da Linguagem) - Instituto de Letras, Universidade Federal do Rio Grande do Sul, 2016.

RIBEIRO, Ana Elisa. Em busca do texto perfeito: questões contemporâneas de edição, preparação e revisão textual. Divinópolis: Artigo A, 2016.

SALGADO, Luciana Salazar. Ritos genéticos editoriais: uma abordagem discursiva da edição de textos. Rev. Inst. Estud. Bras., São Paulo, n. 57, p. 253-276, dez. 2013.

SALGADO, Luciana Salazar. Ritos genéticos editoriais: autoria e textualização. Bragança Paulista: Editora Urutau, 2016.

SCHWARTZ, Yves. Os ingredientes da competência: um exercício necessário para uma questão insolúvel. Educ. Soc. [online], v. 19, n. 65, p.101-140, 1998.

SCHWARTZ, Yves. Motivações do conceito de corpo-si: corpo-si, atividade, experiência. Letras de Hoje, Porto Alegre, v. 49, n. 3, p. 259-274, jul.-set. 2014. 